\title{
Cost effectivenes of erlotinib versus chemotherapy for first-line treatment of non small cell lung cancer (NSCLC) in fit elderly patients participating in a prospective phase 2 study (GFPC 0504)
}

Chouaid Christos $^{1,9^{*}}$, Le Caer Hervé ${ }^{2}$, Locher Chrystelle ${ }^{3}$, Dujon Cecile ${ }^{4}$, Thomas Pascal ${ }^{5}$, Auliac Jean Bernard ${ }^{6}$, Monnet Isabelle ${ }^{7}$, Vergnenegre Alain ${ }^{8}$ and GFPC 0504 Team

\begin{abstract}
Background: The median age of newly diagnosed patients with non-small cell lung cancer (NSCLC) is 67 years, and one-third of patients are older than 75 years. Elderly patients are more vulnerable to the adverse effects of chemotherapy, and targeted therapy might thus be a relevant alternative. The objective of this study was to assess the cost-effectiveness of erlotinib followed by chemotherapy after progression, compared to the reverse strategy, in fit elderly patients with advanced NSCLC participating in a prospective randomized phase 2 trial (GFPC0504).

Methods: Outcomes (PFS and overall survival) and costs (limited to direct medical costs, from the third-party payer perspective) were prospectively collected until second progression. Costs after progression and health utilities (based on disease states and grade 3-4 toxicities) were derived from the literature.
\end{abstract}

Results: Median overall survival, QALY and total costs for the erlotinib-first strategy were respectively 7.1 months, 0.51 and $27734 €$, compared to 9.4 months, 0.52 and $31688 €$ for the chemotherapy-first strategy. The Monte Carlo simulation demonstrates that the two strategies do not differ statistically.

Conclusion: In terms of cost effectiveness, in fit elderly patients with NSCLC, erlotinib followed by chemotherapy compares well with the reverse strategy.

Keywords: Cost-utility, Erlotinib, Non-small cell lung cancer, Elderly patients, Phase II trial

\section{Background}

The US National Institutes of Health estimated that $\$ 89$ billion was spent on cancer care in the United States in 2007, and that the total economic burden reached $\$ 219.2$ billion when indirect costs associated with lost productivity and death were taken into account. Recent trends suggest that the growth in cancer spending will accelerate, owing to costly new treatments and the increasing number of cancer patients. These costs may

\footnotetext{
*Correspondence: Christos.chouaid@sat.aphp.fr

${ }^{1}$ AP-HP Hôpital St-Antoine, AP-HP, UMPC, Paris, France

${ }^{9}$ Service de Pneumologie, Hôpital Saint-Antoine, 84 rue du boulevard Saint-Antoine, 75012, Paris, France

Full list of author information is available at the end of the article
}

increase further still with the introduction of novel targeted therapies [1]. Lung cancer is the second most common malignancy in the US and the leading cause of cancer-related death. Non small-cell lung cancer (NSCLC) accounts for $85 \%$ of lung cancers, and most patients already have advanced or metastatic disease at diagnosis [2]. Between $30 \%$ and $40 \%$ of NSCLC cases are diagnosed in patients over 70 years of age, raising specific issues of age, comorbidity and toxicity [3]. Most elderly patients are either under-treated or receive non validated schedules [3,4]. They are also largely underrepresented in therapeutic trials, and little clinical research takes their specificities into account [4]. The value of specific studies of elderly subjects has been 
clearly demonstrated [4]. The recommended first-line treatment for patients under 65 with metastatic NSCLC and good performance status consists of dual-agent platinum-based chemotherapy. There is no consensus on the management of elderly NSCLC patients, although adapted platinum-based chemotherapy seems feasible in high selected subjects [4-6]. Single-agent and dualagent therapy without a platinum salt also seems possible for patients selected on the basis of a geriatric assessment taking comorbidities into account. Among the available non platinum-based chemotherapy regimens, the docetaxel-gemcitabine (DG) combination is considered one of the most promising [7-9]. Targeted therapies have given promising results in elderly populations. In the pivotal BR21 study, second-line erlotinib had the same efficacy in the subgroup of patients over 70 years old as in the entire population [10]. Targeted therapies are also a potential first-line option for elderly patients with advanced NSCLC [11]. Indeed, erlotinib was well tolerated in this population and there was a significant improvement in key symptoms [11]. One difficulty in this setting is the heterogeneity of elderly populations. The use of a co-morbidity score and a comprehensive geriatric assessment (CGA) can identify a more homogenous group of fit elderly patients [9]. The objective of this cost analysis was to assess the cost-effectiveness of first-line erlotinib followed by chemotherapy after progression, compared to the reverse strategy, in fit elderly patients with advanced NSCLC participating in the GFPC0504 study, a randomized phase 2 trial [12].

\section{Patients and methods}

\section{Study design and population}

The GFPC 0504 study was a multicenter, open-label, randomized phase II trial. It involved patients with previously untreated stage IIIB or IV NSCLC. It compared erlotinib followed, after progression, by weekly chemotherapy (docetaxel $30 \mathrm{mg} / \mathrm{m}^{2}$ for 6 consecutive weeks and gemcitabine $900 \mathrm{mg} / \mathrm{m} 2$ at weeks $1,2,4$ and 5, followed by a two-week treatment-free period) (Arm A) to the reverse strategy (arm B). The primary endpoint was second-progression-free survival. Overall survival was a secondary endpoint.

\section{Costs}

Costs were estimated from perspective the French health care system, from randomization until death. All resources consumed during the first and second treatment lines were prospectively collected on a per patient basis. Resources consumed were comprised of chemotherapy drugs, erlotinib, supportive treatments (including recombinant human erythropoietin, antiemetics, colony-stimulating factors, antibiotics, management of adverse effects, etc.), transfusion, and hospitalization for any reason. The specific unit costs are reported in Table 1 $[13,14]$. Costs incurred after the second disease progression period were derived from a representative French nationwide sample of 428 patients, using chart review to assess the mean direct monthly cost of NSCLC patient management after the second line progression [15]. Specifically, the costs included outpatient and inpatient services, care provision at skilled nursing facilities, outpatient and inpatient drugs and other medications, nursing care organization, home health visits (including medications), and durable medical equipment. Assuming a yearly increment of $3.5 \%$, one month of palliative care cost 2324 euros (2011 value).

\section{Utilities}

Utilities were derived from UK community populationbased studies in advanced NSCLC [16,17], which used the standard gamble interview and visual analog scales to assess quality of life (Table 1).

\section{Cost-utility analysis}

The incremental cost-effectiveness ratios (ICER) were calculated. These ratios correspond to the difference in costs divided by the difference in effectiveness (expressed in QALY) between two strategies.

\section{Statistical analysis}

Second-progression-free survival was calculated from randomization to disease progression (after the second line of treatment if the patients received 2 lines, after the first line if the patient progressed and did not receive a second line), or death of any cause, or the last

Table 1 Model inputs

\begin{tabular}{lllll}
\hline & \multicolumn{4}{l}{ Estimates } \\
\hline Health state utilities & 0.673 & 0.27 & 0.80 & {$[16,17]$} \\
Stable disease on oral therapy & 0.653 & 0.26 & 0.78 & {$[16,17]$} \\
Stable disease on IV therapy & 0.473 & 0.19 & 0.56 & {$[16,17]$} \\
Progressive disease & 0 & & & {$[16,17]$}
\end{tabular}

Death

\begin{tabular}{|c|c|c|}
\hline Cost of medical services and drugs $(€)$ & 2174.7 & $16273021 \quad[12,13]$ \\
\hline Erlotinib 30 days supply (150 mg) & $9.1 / \mathrm{mg}$ & {$[12,13]$} \\
\hline Docetaxel & $0.2 / \mathrm{mg}$ & {$[12,13]$} \\
\hline Gemcitabine & 368 & {$[12,13]$} \\
\hline Hospitalization at home (day) & 422 & {$[12,13]$} \\
\hline Day-ward hospital & 557.40 & {$[12,13]$} \\
\hline G-CSF injection (per cycle) & 220.53 & {$[12,13]$} \\
\hline Erythropoietin (per injection) & 2324 & [15] \\
\hline $\begin{array}{l}\text { Palliative care after progression } \\
\text { (per month) }\end{array}$ & & \\
\hline
\end{tabular}


on-trial tumor assessment. OS was calculated from randomization to death from any cause, or the last date the patient was known to be alive. PFS and OS were assessed by the Kaplan-Meier method. Statistical analyses used SAS software version 9.01 (Institute INC, Carry, USA).

\section{Assessing uncertainty}

The uncertainty was evaluated by using one-way sensitivity analysis, sequentially varying the estimates for a given model parameter while keeping the other parameters constant, within a range of likely values derived from confidence intervals or reasonable ranges as determined from published sources. In addition, multivariate probabilistic sensitivity analysis was performed using second-order Monte Carlo simulation, in which the model inputs (time to second progression, OS, utilities and costs) were drawn from individual data. Specific distributions were assigned to utility data by using published means and standard deviations to specify the normal distribution. A simulation with 10000 replications of the model was then used to obtain the $95 \%$ nonparametric confidence intervals for the costs and effectiveness parameters, and to determine the proportion of replications in each quadrant of the cost-effectiveness plane. The multiway sensitivity analysis was presented in radar screen format, in which the $\mathrm{X}$-axis shows the difference in effectiveness and the Y-axis the difference in costs between two strategies. The 10000 replications are represented by dots.

\section{Results}

Between July 2006 and November 2008, 22 centers enrolled 100 patients in this study. Demographic variables measured int the two groups did not differ in a statistically way (Table 2). As already reported, there was no significant difference in the Charlson scores, co-morbidities, or geriatric assessment scores [12]. There was no significant difference between the two arms in terms of the time to second progression (5.8 and 7.5 months respectively in arms $\mathrm{A}$ and $\mathrm{B}, \mathrm{p}=0.53$ ) or median OS (7.1 and 9.4 months, $\mathrm{p}=0.26$ ); QALY values were respectively $0.51 \pm 0.44$ and $0.52 \pm 0.41$ and costs were $27734 \pm 19801$ and $31688 \pm 22693 €$. The distribution of these costs differed between the two arms: palliative care represented respectively $21.4 \%$ and $30.0 \%$ of total costs; chemotherapy $8.6 \%$ and $17.6 \%$, and erlotinib $41.5 \%$ and $19.7 \%$, in arms $\mathrm{A}$ and $\mathrm{B}$ (Figure 1). The Monte Carlo simulation demonstrates that the two strategies do not differ statistically. Multivariate probabilistic sensitivity analysis (results of 10000 replications) showed that the two strategies had equivalent costeffectiveness (Figure 2), as confirmed by varying the utility values and the cost of palliative care (Table 3).
Table 2 Patients characteristics: Arm A: erlotinib followed by docetaxel plus gemcitabine (DG) after progression; Arm B: DG followed by erlotinib after progression (* no significant difference, ${ }^{* *} p=0.013$ )

\begin{tabular}{lll}
\hline & Arm A & Arm B \\
\hline Age mean (years) & $\mathbf{n}=\mathbf{4 8}$ & $\mathbf{n}=\mathbf{5 1}$ \\
Gender male (\%) & $76 \pm 5$ & $76 \pm 4_{-}^{*}$ \\
Smoker & $29(60 \%)$ & $30(59 \%)_{-}^{*}$ \\
Current & $6(13 \%)$ & $8(16 \%)_{-}^{*}$ \\
Former & $26(54 \%)$ & $25(49 \%)$ \\
Never smoker & $15(31 \%)$ & $15(29 \%)$ \\
Unknown & $1(2 \%)$ & $3(6 \%)$ \\
Performance status & & \\
0 & $22(47 \%)$ & $21(41 \%)_{-}^{*}$ \\
1 & $21(45 \%)$ & $28(55 \%)$ \\
2 & $4(9 \%)$ & $2(4 \%)$ \\
Stage & & \\
IIIB & $6(13 \%)$ & $4(8 \%)_{-}^{*}$ \\
IV & $42(87 \%)$ & $47(92 \%)$ \\
Histology & & \\
Squamous cell & $11(23 \%)$ & $8(16 \%)_{-}^{* *}$ \\
Adenocarcinoma & $28(58 \%)$ & $29(57 \%)$ \\
Undifferentiated & $9(19 \%)$ & $14(28 \%)$ \\
Second line treatment & & $24(47 \%)^{* *}$ \\
\hline
\end{tabular}

\section{Discussion}

This analysis showed no significant difference in patient outcomes between first-line erlotinib followed by chemotherapy after progression and the reverse sequence. However, the erlotinib-first strategy was less costly, and the ICER of the chemotherapy-first strategy relative to the erlotinib-first strategy was $395400 €$ per QALY. These results were obtained in a highly specific population of fit elderly patients selected with a CGA. The main originality of this study is that the second-line treatment was fixed in each arm, thus allowing us to evaluate the performance of the entire treatment strategies. In advanced NSCLC, economic analyses are usually limited to either first- or second-line treatment. Sand studies of doublets without platinum salts are rare in the first-line setting [2].

A study done in Greece [18] compared the docetaxel/ gemcitabin combination with docetaxel monotherapy in untreated patients with advanced NSCLC. It showed an incremental cost per life-year gained (LYG) of 9538 euros with the combination. The probability of being cost-effective was $91 \%$ at a threshold of 20000 euros, $97 \%$ at 35000 euros and $98 \%$ at 50000 euros. 


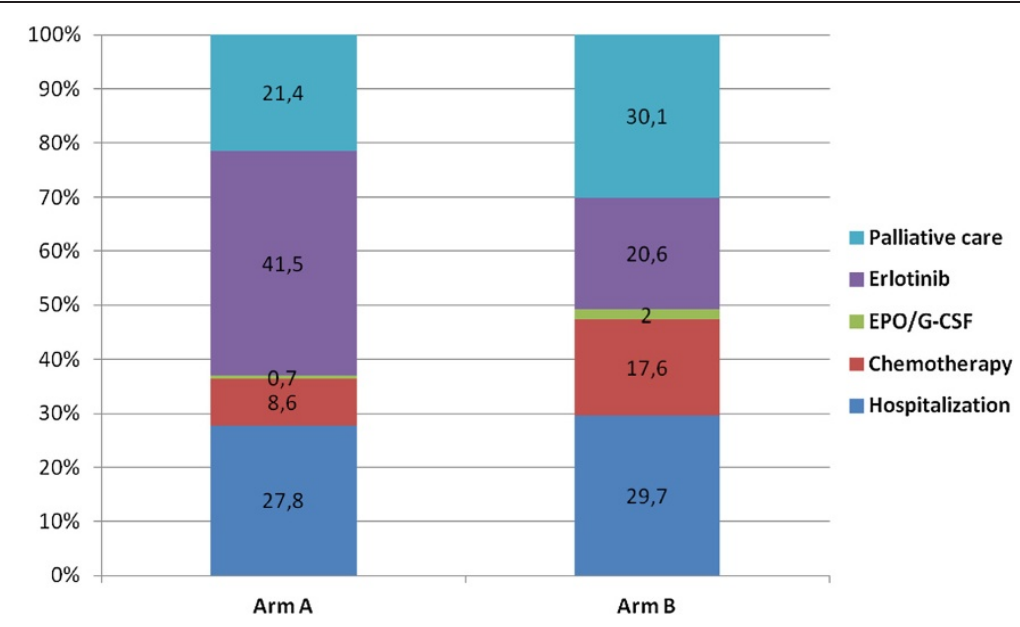

Figure 1 Per patient mean cost in Arm A (erlotinib followed by docetaxel and gemcitabine (DG) and Arm B (DG followed by erlotinib).

In the second-line setting, the ICER of erlotinib versus placebo [19] was explored by using resource utilization determined from individual patient data in the BR.21 trial database (a pivotal trial in this setting). The trial involved 731 patients (488 in the erlotinib arm and 243 in the placebo arm). The ICER of erlotinib was $\$ 94.638$ per LYG (95\% confidence interval $=\$ 52359$ to $\$ 429$ 148). The major drivers of cost-effectiveness included the magnitude of the survival benefit and the cost of erlotinib. Subgroup analyses suggested that erlotinib might be more costeffective in never-smokers. There was no specific analysis of elderly patients included in this study.
The cost-effectiveness of erlotinib has also been compared with that of other agents (docetaxel and pemetrexed) licensed for second-line treatment of advanced NSCLC [20]. In a model-based analysis, second-line treatment with erlotinib, docetaxel and pemetrexed yielded respectively $0.42,0.41$, and 0.41 QALY, and total costs were US\$ 37 000, 39100 and 43 800. Again, there was no specific analysis of elderly patients. A more recent cost-utility analysis compared erlotinib and docetaxel for second-line management of advanced NSCLC within the UK National Health Service. The authors used a health-state transition model, based on the two

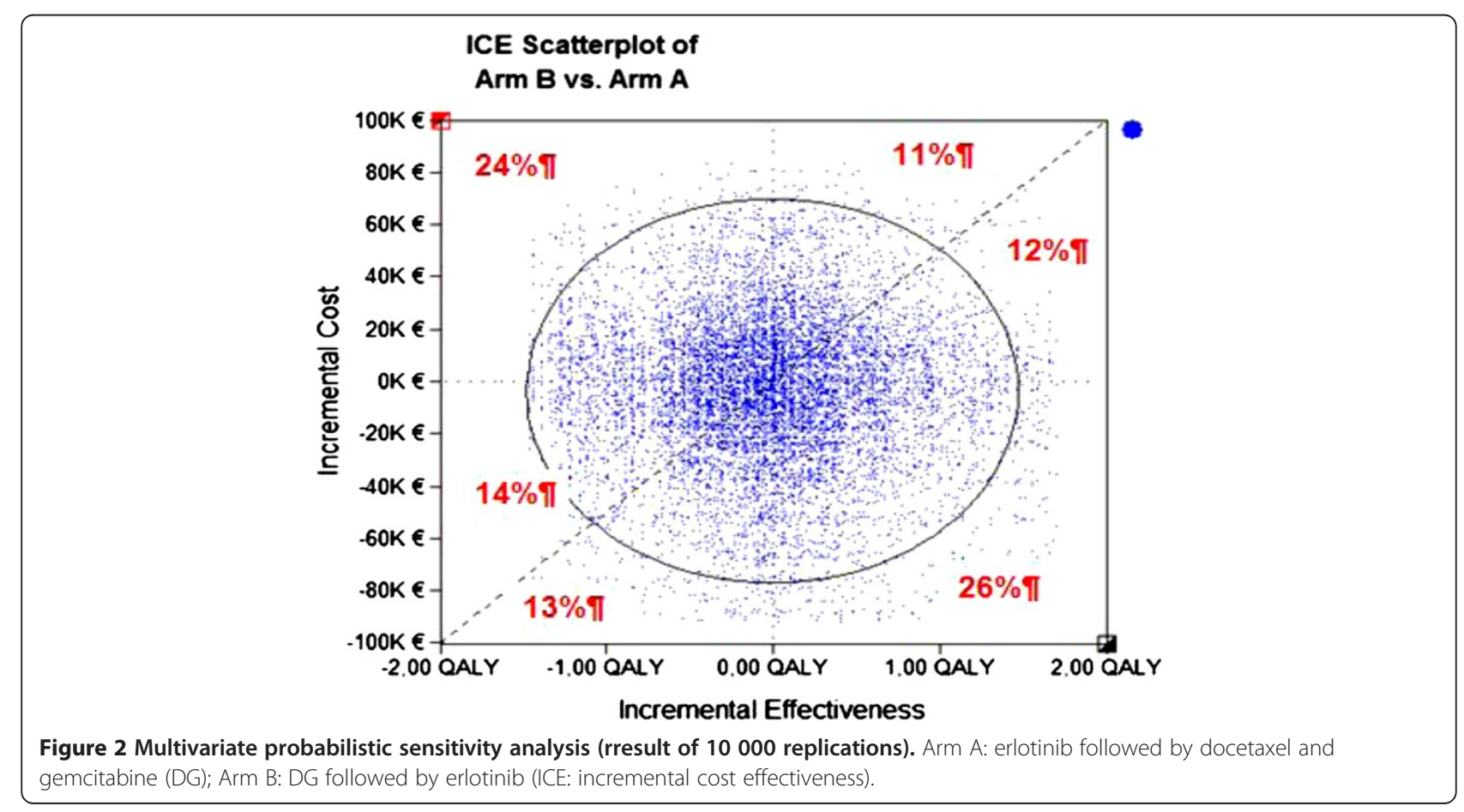


Table 3 One way sensitivity analysis

\begin{tabular}{|c|c|c|c|}
\hline & Arm A & Arm B & ICER B/A \\
\hline & $\overline{\text { Costs } € / \text { utility }}$ & $\overline{\text { Costs } € / \text { utility }}$ & €/QALY \\
\hline Base case & $27734 € / 0.51$ & $31688 € / 0.52$ & 395400 \\
\hline \multicolumn{4}{|c|}{$\begin{array}{l}\text { Utility of patients } \\
\text { treated by erlotinib }\end{array}$} \\
\hline$-20 \%(0.538)$ & $27734 € / 0.48$ & $31688 € / 0.51$ & 131800 \\
\hline$-10 \%(0.606)$ & $27734 € / 0.51$ & $31688 € / 0.52$ & 395400 \\
\hline$+10 \%(0.740)$ & $27734 € / 0.54$ & $31688 € / 0.54$ & NA \\
\hline$+20 \%(0.807)$ & $27734 € / 0.57$ & $31688 € / 0.55$ & NA \\
\hline \multicolumn{4}{|c|}{ Post-progression cost } \\
\hline $1627 €$ & $25954 € / 0.51$ & $28787 € / 0.52$ & 283300 \\
\hline $3021 €$ & $29514 € / 0.51$ & $34588 € / 0.52$ & 507400 \\
\hline \multicolumn{4}{|c|}{ Erlotinib tariff } \\
\hline$-30 \%$ & $24282 € / 0.51$ & $29788 € / 0.52$ & 550600 \\
\hline$+30 \%$ & $31186 € / 0.51$ & $33588 € / 0.52$ & 240200 \\
\hline
\end{tabular}

Arm A: erlotinib followed by docetaxel and gemcitabine (DG); Arm B: DG followed by erlotinib.

pivotal phase III studies of erlotinib versus best supportive care and docetaxel versus best supportive care, to estimate direct costs, QALY, and the subsequent net monetary benefit. Erlotinib was associated with lower total costs ( $£ 13730$ versus $£ 13$ 956) and a gain in QALY [16]. In a recently, retrospective real world costeffectiveness study, on second line setting, erlotinib and docetaxel are statistically equivalent in terms of treatment costs and overall survival [21].

Regarding the burden of NSCLC in terms of healthrelated quality of life, little information is available on the preferences of patients or society with respect to disease states [22,23]. We used data from Nafees et al. [17], who adapted existing health-state descriptions in metastatic breast cancer to evaluate the utilities of patients receiving second-line treatment for NSCLC. Each health state describes the symptom burden of a disease and its functional impact. More recently, Lewis [16] used the same method to establish health utilities for erlotinib therapy, based on data for 154 members of the UK general population, using the euroQol EQ-5D instrument. We used the results of both studies to test the robustness of our model with varying utility values.

One advantage of our study is the prospective collection of cost data, at least until second progression. In contrast, management costs after the end of active treatments were derived from a 2004 national database. In addition, our analysis was limited to direct lung cancerrelated medical costs: indirect costs such as lost productivity and caregiver salaries were not included. Also, the way in which we expressed utilities reflects the value from the point of view of society rather than that of the patients concerned. Finally, it is uncertain whether these utilities are fully relevant to our population of elderly patients. However, our sensitivity analyses compensated for these limitations, as the conclusions based on the base-case scenario were unaffected when we varied the different model parameters. One limitation of our analysis is that EGFR patients status was not knew and we a unable to analyze the ICER of erlotinib first line treatment in the subgroup of patient with a EGFR mutation.

\section{Conclusion}

In terms of cost-effectiveness, in fit elderly patients with NSCLC, erlotinib followed by chemotherapy compares well with the reverse strategy.

\section{Competing interests}

C Chouaid has received consultancy fees (less than 10000 USD) from Roche Pharmaceuticals, Amgen, GSK, Astra Zeneca and Lilly. A Vergnenegre has received consultancy fees (less than 10000 USD) from Roche

Pharmaceuticals, Astra Zeneca and Lilly. The other authors declare that they have no conflicts of interest.

\section{Authors' contributions}

C. Chouaid had full control of the study design, data analysis and interpretation, and manuscript preparation. CC, LH and VA conceived and performed the statistical analysis, LC, DC, TP and IM particped in the design and ccordination and helped to draft the manuscript. The final draft manuscript was approved by all the authors.

\section{Prior presentation}

This study has previously been presented at the 2010 European Ispoor meeting in Prague, Czech Republic.

\section{The GFPC0504 team}

Pr. Vergnenegre A, Pr. Melloni B, CHU Limoges;

Pr Prof Barlesi F, Dr Greillier L, CHU Marseille;

Dr LeCaer H, Dr Barriere JR, CH Draguignan;

Dr Gerinière L, CHU Lyon;

Dr Bombaron P, CH Mulhouse;

Dr Crequit J, CH Beauvais;

Dr Auliac JB CH Mantes;

Dr Le Treut J, CH Aix;

Dr Berard H, HIA Toulon;

Dr Thomas P, Dr Muller P, CH Gap;

Dr Fournel P CHU St Etienne;

Dr Robinet G, Dr Andre M, CHU Brest;

Dr Grivaux M, Dr Locher C CH Meaux;

Dr .Berdah JF Clinique Esperance Hyeres;

Pr. Chouaid C, Dr Baud M CHU Paris St Antoine;

Dr Bota S, CHU Rouen CN;

Dr Paillotin D CHU Rouen BG;

Dr Corre R, Dr Lena H CHU Rennes;

Dr Chouabe S, CH Charleville;

Dr Delhoume JY CH Perigueux;

Dr Dujon C CH Le Chesnay;

Dr Jullian $\mathrm{H}$, Dr .Simonian $\mathrm{H}, \mathrm{CH}$ Martigues;

Dr David P, CH Elbeuf;

Dr Falchero L, CH Villefranche;

Dr Janicot H, CHU Clermont-Ferrand;

Dr Monnet I, CHI Creteil

\section{Acknowledgments}

This trial was an academic trial conducted by Groupe Français de PneumoCancérologie and sponsored by Limoges University Hospital (France).

Sources of funding included public funding and an unrestricted grant from F. Hoffmann-La Roche Ltd. 


\section{Author details}

${ }^{1}$ AP-HP Hôpital St-Antoine, AP-HP, UMPC, Paris, France. ${ }^{2} \mathrm{CH}$ de Draguignan, Draguignan, France. ${ }^{3} \mathrm{CH}$ de Meaux, Meaux, France. ${ }^{4} \mathrm{CHI}$ de Versailles, Versailles, France. ${ }^{5} \mathrm{CH}$ de Gap, Paris, France. ${ }^{6} \mathrm{CH}$ de Mantes La Jolie, Mantes La Jolie, France. ${ }^{7} \mathrm{CHI}$ de Creteil, Creteil, France. ${ }^{8} \mathrm{CHU}$ de Limoges, Limoges, France. ${ }^{9}$ Service de Pneumologie, Hôpital Saint-Antoine, 84 rue du boulevard Saint-Antoine, 75012, Paris, France.

Received: 12 February 2012 Accepted: 27 June 2012

Published: 20 July 2012

\section{References}

1. Yabroff KR Lund J, Kepka D, Mariotto A: Economic burden of cancer in the United States: estimates, projections, and future research. Cancer Epidemiol Biomarkers Prev 2011, 20:2006-2014.

2. Chouaid C, Atsou K, Hejblum G, Vergnengre A: Economics of treatments for non-small cell lung cancer. PharmacoEconomics 2009, 27:113-125.

3. Pallis AG, Georgoulias V: Is there a standard regimen for first-line treatment of advanced/metastatic Non-Small-Cell Lung Cancer? Lung Cancer: What has meta-analyses contributed to today's standard of care; 2011.

4. Jatoi A, Hillman S, Stella P, Green E, Adjei A, Nair S, Perez E, Amin B, Schild SE, Castillo R, Jett JR: North Central Cancer Treatment Group. Should elderly non-small-cell lung cancer patients be offered elderly-specific trials? Results of a pooled analysis from the North Central Cancer Treatment Group. J Clin Oncol 2005, 23:9113-9119.

5. Gridelli C, Maione P, Illiano A, Piantedosi FV, Favaretto A, Bearz A, Robbiati SF, Filipazzi V, Lorusso V, Carrozza F, laffaioli RV, Manzione L, Gallo C, Morabito A, Perrone F: Cisplatin plus gemcitabine or vinorelbine for elderly patients with advanced non small-cell lung cancer: the MILES 2P studies. J Clin Oncol 2007, 25:4663-4669.

6. Quoix E, Zalcman G, Oster JP, Westeel V, Pichon E, Lavolé A, Dauba J, Debieurre D, Souquet PJ, Bigay-Game L, Dansin E, Poudenx M, Molinier O, Vaylet F, Moro-Sibilot D, Herman D, Bennouna J, Tredaniel J, Ducoloné A, Lebitasy MP, Baudrin L, Laporte S, Milleron B: Intergroupe Francophone de Cancérologie Thoracique: Carboplatin and weekly paclitaxel doublet chemotherapy compared with monotherapy in elderly patients with advanced non-small-cell lung cancer: IFCT-0501 randomised, phase 3 trial. Lancet 2011, 378:1079-1088.

7. LeCaer $\mathrm{H}$, Fournel $\mathrm{P}$, Jullian $\mathrm{H}$, Chouaid C, Letreut J, Thomas P, Paillotin D, Perol M, Gimenez C, Vergnenegre A: An open multicenter phase II trial of docetaxel-gemcitabine in Charlson score and performance status selected elderly patients with stage IIIB pleur /IV non-small-cell lung cancer: The GFPC 02-02a study. Crit Rev Oncol Hematol 2007, 64:73-81.

8. Pujol JL, Breton JL, Gervais R, Rebattu P, Depierre A, Morère JF, Milleron B, Debieuvre $D$, Castéra $D$, Souquet PJ, Moro-Sibilot D, Lemarié E, Kessler R, Janicot H, Braun D, Spaeth D, Quantin X, Clary C: Gemcitabine-docetaxel versus cisplatin-vinorelbine in advanced or metastatic non-small cell lung cancer: a phase III study addressing the case for cisplatin. Ann Oncol 2005, 16:602-610.

9. Pallis AG, Gridelli C, van Meerbeeck JP, Greillier L, Wedding U, Lacombe D, Welch J, Belani CP, Aapro M: EORTC Elderly Task Force and Lung Cancer Group and International Society for Geriatric Oncology(SIOG): experts' opinion for the treatment of non-small-cell lung cancer in an elderly population. Ann Oncol 2010, 21:692-706.

10. Wheatley-Price P, Ding K, Seymour L, Clark GM, Shepherd FA: Erlotinib for advanced non-small-cell lung cancer in the elderly: an analysis of the National Cancer Institute of Canada Clinical Trials Group Study BR 21. J Clin Oncol 2008, 26:2350-2357.

11. Jackman DM, Yeap BY, Lindeman NI, Fidias P, Rabin MS, Temel J, Skarin AT, Meyerson M, Holmes AJ, Borras AM, Freidlin B, Ostler PA, Lucca J, Lynch TJ, Johnson $B E$, Jänne PA: Phase II clinical trial of chemotherapy-naive patients $>$ or $=70$ years of age treated with erlotinib for non-small-celllung advanced cancer. J Clin Oncol 2007, 25:760-766.

12. Lecaer $H$, Barlesi F, Corre $R$, Jullian $H$, Bota S, Falchero L, Vergnenegre A, Dujon C, Delhoume JY, Chouaid C: A multicentre phase II randomised trial of weekly docetaxel/gemcitabine followed by erlotinib on progression, vs the reverse sequence, in elderly patients with advanced non smallcell lung cancer selected with a comprehensive geriatric assessment (the GFPC 0504 study). Br J Cancer 2011, 105:1123-1130.

13. Ministère de la Santé et des Solidarités: Arrêté du 27 février 2007 relatif à la classification et à la prise en charge des prestations d'hospitalisation pour les activités de médecine, chirurgie, obstétrique et odontologie et pris en application de l'article L. 162-22-6 du code de la sécurité sociale. Journal Officiel 2007, 50:28-72.

14. Nomenclature Générale des Actes Professionnels: Union des Caisses Nationales de Sécurité Sociale (UCANSS). http://www.ameli.fr/fileadmin/ user_upload/documents/NGAP-oct-2009.pdf.

15. Chouaid C, Molinier L, Combescure C, Daurès JP, Housset B, Vergnenègre A: Economics of the clinical management of lung cancer in France: an analysis using a Markov model. Br J Cancer 2004, 90:397-402.

16. Lewis G, Peake M, Aultman R, Gyldmark M, Morlotti L, Creeden J, de la Orden M: Cost-effectiveness of erlotinib versus docetaxel for second-line treatment of advanced non-small-cell lung cancer in the United Kingdom. J Int Med Res 2010, 38:9-21.

17. Nafees B, Stafford M, Gavriel S, Bhalla S, Watkins J: Health state utilities for non small cell lung cancer. Health and Quality of Life Outcome 2008, 6. http://www.ncbi.n/m.nih.gov/pmc/articles/PMC2579282/pdf/1477-7525-6-84. pdf.

18. Maniadakis N, Fragoulakis V, Pallis A, Prezerakos P, Georgoulias V: Economic evaluation of docetaxel/gemcitabine versus docetaxel as frontline treatment of patients with advanced/metastatic non-small cell lung cancer in Greece. Lung Cancer 2007, 58:275-81.

19. Bradbury PA, Tu D, Seymour L, Isogai PK, Zhu L, Ng R, Mittmann N, Tsao MS, Evans WK, Shepherd FA, Leighl NB: NCIC Clinical Trials Group Working Group on Economic Analysis: Economic analysis: randomized placebocontrolled clinical trial of erlotinib in advanced non-small cell lung cancer. J Natl Cancer Inst 2010, 102:298-306.

20. Carlson JJ, Reyes C, Oestreicher N, Lubeck D, Ramsey SD, Veenstra DL: Comparative clinical and economic outcomes of treatments for refractory non-small cell lung cancer (NSCLC). Lung Cancer 2008, 61: 405-15.

21. Cromwell I, van der Hoek K, Melosky B, Peacock S: Erlotinib or docetaxel for second-line treatment of non-small cell lung cancer: a real-world cost-effectiveness analysis. J Thorac Oncol 2011, 6:2097-103.

22. Tabberer M, Stamuli E, Walker M: Utilities associated with non-small cell lung cancer (NSCLC): a community study. Value Health 2006, 9:A298.

23. Trippoli S, Vaiani M, Lucioni C, Messori A: Quality of life and utility in patients with non-small cell lung cancer. Quality-of-life Study Group of the Master 2 Project in Pharmacoeconomics. PharmacoEconomics 2001, 19:855-63.

doi:10.1186/1471-2407-12-301

Cite this article as: Chouaid et al:: Cost effectivenes of erlotinib versus chemotherapy for first-line treatment of non small cell lung cancer (NSCLC) in fit elderly patients participating in a prospective phase 2 study (GFPC 0504). BMC Cancer 2012 12:301.

\section{Submit your next manuscript to BioMed Central and take full advantage of:}

- Convenient online submission

- Thorough peer review

- No space constraints or color figure charges

- Immediate publication on acceptance

- Inclusion in PubMed, CAS, Scopus and Google Scholar

- Research which is freely available for redistribution 